\title{
PEMILIHAN LOKASI PERHUTANAN SOSIAL DI KECAMATAN KAMANG BARU KABUPATEN SIJUNJUNG
}

\author{
Asef Tionanda ${ }^{1}$, Ahyuni, ST, M.Si ${ }^{2}$, Drs. Helfia Edial, M.T ${ }^{2}$ \\ Program Studi Geografi \\ Fakultas Ilmu Sosial Universitas Negeri Padang \\ e-mail : aseftionanda43@gmail.com
}

\begin{abstract}
ABSTRAK
Penelitian ini bertujuan untuk mengetahui lokasi hutan yang cocok dijadikan perhutanan sosial di Kecamatan Kamang Baru, dan Kesiapan masyarakat terhadap rencana pengembangan perhutanan sosial di Kecamatan Kamang Baru. Jenis penelitian ini bersifat penelitian campuran (mixed method). Pengambilan sampel dengan metode Total Sampling dengan teknik overlay dan penarikan kesimpulan dari hasil wawancara di lapangan. Hasil penelitian: (1) Dari 11 Kenagarian yang terdapat di Kecamatan Kamang Baru terpilih 7 nagari yang memiliki lahan prioritas untuk perencanaan perhutanan sosial yaitu nagari Sungai Lansek dengan luas 265 ha, Muaro Takuang dengan luas 318 ha, Aia Amo dengan luas 1784 ha, Maloro dengan luas 73 ha, Padang Tarok dengan luas 4181 ha, Sungai Betung dengan luas 955 ha, Siaur dengan luas 380 ha. Jumlah luas keseluruhan perhutanan sosial Kecamatan Kamang Baru 7956 ha. (2) Berdasarkan kriteria penentuan kesiapan masyarakat terhadap perencanaan perhutanan sosial (biofisik, kelembagaan, dan ekonomi) terdapat 2 nagari dengan kategori sangat siap yaitu Sungai Betung dan Lubuk Tarantang, 3 nagari dengan kategori siap yaitu Sungai Lansek, Muaro Takuang, dan Aia Amo, 1 nagari dengan kategori cukup siap yaitu Nagari Siaur.

Kata Kunci: Pemilihan Lokasi, Perhutanan Sosial
\end{abstract}

ABSTRACT

This research intend to know about forest location which are suitable to be social forest at Kamang Baru Sub-District, and community readiness for social forest development plan at Kamang Baru Sub-District. This research use mix method as types of research. Sampling is done by Total Sampling method with overlay technique and interview results summary. The results of research are : (1) from 11 villages in Kamang Baru Sub-District only 7 villages that have land priority for social forest plan, that is Sungai Lansek with size is 265 ha, MuaroTakuang 318 ha, Aia Amo 1748 ha, Maloro 73 ha, Padang Tarok 4181 ha, Sungai Betung 955 ha, Siaur 380 ha. Total number area of social forest at Kamang Baru Sub-District is 7956 ha. (2) based on criteria for determining community readiness for social forest plan (biophysic, institutional, and economic) there are 2 villages in the very ready categories, Sungai Betung and Lubuk Tarantang, 3 villages with the categories is ready, Lansek, Muaro Takuang, dan Aia Amo, 1 villages with the categories is quite ready, Siaur.

Keyword: Location Selection, Social Forest

\footnotetext{
${ }^{1}$ Artikel ini ditulis dari skripsi penulis dengan judul Pemilihan Lokasi Perhutanan Sosial di Kecamatan Kamang Baru Kabupaten Sijunjung untuk wisuda periode september 2018 dengan ${ }^{2}$ Pembimbing I Ahyuni, ST, M.Si, dan Pembimbing II Drs. Helfia Edial, M.T.
} 


\section{PENDAHULUAN}

Perusakan hutan masih mengancam hutan Indonesia. Tekanan terhadap sumberdaya hutan menyebabkan terjadinya eksploitasi yang berlebihan, sehingga sumberdaya hutan tidak mampu lagi memberikan manfaat yang optimal. Tekanan yang berlebihan juga menyebabkan sumberdaya hutan mengalami kerusakan dan menurunnya produktivitas. Saat ini tingkat kerusakan hutan di Indonesia makin tinggi. Deforestasinya sudah mencapai 2,83 juta hektare per tahun. Data terakhir menunjukan dari total kawasan hutan seluas 120,35 juta hektar, lebih dari 59 juta hektar kondisinya rusak dan sangat memprihatinkan (Kementrian Lingkungan Hidup dan Kehutanan, 2005).

Kerusakan kawasan hutan menyebabkan timbulnya berbagai permasalahan lingkungan. Pada musim kemarau hutan yang rusak sangat mudah terbakar. Kebakaran hutan serta asap yang ditimbulkannya sudah menjadi permasalahan nasional tiap tahun dan sampai saat ini belum dapat teratasi. Pada musim hujan terjadi bencana banjir yang terjadi hampir di seluruh wilayah Indonesia.

Sumatra Barat memiliki kekayaan hutan yang sangat melimpah dengan luas $\pm \quad 56.3 \%$ dari luas wilayah administrasinya, yang tersebar di setiap kabupaten kota salah satunya di kabupaten sijunjung, dengan besarnya luasan hutan yang dimiliki membuat masyarakat menggantungkan kehidupan di dalam nya, tampa pengelolaan yang berbasis lingkungan mengakibatkan kerusakan pada hutan itu sendiri. Kerusakan hutan itu diakibatkan pembalakan liar, pembakaran hutan, perubahan fungsi lahan seperti yang juga terjadi di Kecamatan Kamang Baru, namun tidak dapat di pungkiri masyarakat yang tingal dsekitar hutan menggantungkan kehidupanya pada hasil hutan untuk memenuhi kebutuhan hidup serta meningkatkan kesejahteraan hidupnya.

Mengingat pentingnya fungsi hutan bagi masyarakat sehingga berkembang kearifan lokal yang ditujukan untuk menjaga kelestarian fungsi lingkungan hidup. Berbagai skema pengelolaan hutan telah diciptakan sebagai respon dari berbagai gejolak dan konflik kehutanan yang muncul. Skema yang digadang-gadangkan oleh Kementrian Kehutanan adalah Pengelolaan Hutan Berbasis Masyarakat (PHBM). Skema ini secara konseptual merupakan pilihan langkah yang tepat. Hanya saja pada tahap implementasinya masih diperlukan serangkaian langkah penyempurnaan.

Pengelolaan Hutan Berbasis Masyarakat PHBM sendiri dibagi melalui skema hutan Desa/Nagari. Hutan Kemasyarakatan (HKM), Hutan Tanam Rakyat (HTR). Pada intinya program tersebut memberikan ruang kepada masyarakat yang berada di pinggiran maupun di dalam kawasan hutan untuk mengelola dan memanfaatkan hutan sebagai upaya untuk pemberdayaan masyarakat setempat. Sehingga dari 
skema ini diharapkan masyarakat bisa meningkatkan kesejahteraan itu sendiri.

Program kehutanan ini merupakan salah satu bentuk perubahan paradigma pemerintah dalam menjaga kelestarian hutan yang dimana masyarakat diikutsertakan dan memperoleh hak atas sumber daya alam yang merupakan bagian penting dalam hidup mereka.(POKJA timbulun, 2014).

Perhutananan sosial ditafsirkan berbeda-beda oleh berbagai pihak di beberapa Negara. Perhutanan sosial dianggap sebagai payung dari berbagai bentuk pengelolaan hutan berbasis masyarakat yang berorientasi pada perbaikan kesejahteraan rakyat. Perhutanan sosial merupakan sistem dan bentuk pengelolaan hutan yang melibatkan peran serta berbagai pihak yang dapat dilakukan dimanasaja, dilahan milik pribadi, umum atau kawasan hutan yang diizinkan di indonesia digunakan berbagai istilah seperti hutan kemasyarakatan, hutan kerakyatan dan kehutanan masyarakat (CIFOR, 2012).

Program perhutanan sosial dapat mengambil peran ke depan untuk mengakomodir keinginan, hasrat dan harapan masyarakat dalam pengelolaan hutan. Pengembangan social forestry dalam pengelolaan hutan harus dapat membalikkan paradigma dari pendekatan yang bersifat partisipatif dan mengutamakan partisipasi masyarakat setempat. Strategi optimum pengembangan social forestry untuk masyarakat adalah pemberian kesempatan pengelolaan hutan kepada masyarakat dengan ketentuan- ketentuan yang memberi insentif pada efesiensi dan keberlanjutan usaha dan kelestarian hutannya, tanpa harus membagi-bagi dan menyerahkan kepemilikan areal hutan pada masyarakat pelaku ekonomi (Hakim, 2010). Skema perhutanan sosial terbagi atas beberapa macam sebagai berikut:

Hutan Desa (HD) Hutan negara yang dikelola oleh desa dan dimanfaatkan untuk kesejahteraan desa. Hak pengelolaan diberikan kepada lembaga pengelola pengelola hutan desa atau lembaga adat yang diatur dengan peraturan desa atau adat.

Hutan Kemasyarakatan (HKm) Hutan negara yang pemanfaatan utamanya ditujukan untuk memberdayakan masyarakat. Pihak yang dapat menjadi pemohon untuk $\mathrm{HKm}$ ini adalah ketua kelompok masyarakat, ketua gabungan kelompok tani hutan, ketua koperasi.

Hutan Tanaman Rakyat (HTR) Hutan tanaman pada hutan produksi yang dibangun olehmkelompok masyarakat untuk meningkatkan potensi dan kualitas hutan produksi dengan menerapkan silvikultur dalam rangka menjamin kelestarian sumber daya hutan. Pihak yang dapat memohonkan HTR ini adalah perorangan (petani hutan), kelompok tani hutan, gabungan kelompok tani hutan, koperasi petani hutan, maupun perorangan yang bekerja sama dengan masyarakat setempat.

Hutan Adat (HA) Hutan yang berada di dalam wilayah masyarakat hukum adat. Artinya pengelolaan hutan 
secara penuh ada di tangan masyarakat hukum adat.

Menurut Arikunto (2004), "Kesiapan adalah suatu kompetensi sehingga seseorang yang mempunyai kompetensi tersebut memiliki kesiapan yang cukup untuk berbuat sesuatu". Hal ini berarti kesiapan adalah suatu keadaan yang dialami seseorang dan orang tersebut telah siap untuk melaksanakan sesuatu.

Kesiapan merupakan suatu kemampuan yang dimiliki seseorang untuk melakukan sesuatu sesuai dengan situasi kondisi yang ada. Kondisi yang dimiliki seseorang sangat berpengaruh terhadap adanya kesiapan dan respon yang akan diberikan oleh seseorang tersebut. Hal ini sama dengan apa yang di ungkapkan Slameto (2010), "Kesiapan adalah keseluruhan kondisi yang membuatnya siap untuk memberi respon atau jawaban di dalam cara tertentu terhadap suatu situasi. Penyesuaian kondisi pada suatu saat akan berpengaruh pada kecenderungan untuk memberi respon". Singkatnya bahwa kesiapan merupakan suatu keadaan siap untuk memberikan respon atau jawaban akan sesuatu dengan cara tertentu untuk menjawab atau merespon tergantung oleh situasi yang dihadapinya. Hasil respon atau jawaban tersebut dipengaruhi oleh keadaan yang sedang dialami seseorang tersebut.

Dilihat dari pendapat-pendapat para ahli, maka dapat disimpulkan bahwa kesiapan adalah suatu kondisi di mana seseorang bersedia, siap dan dapat melaksanakan sesuatu untuk mencapai sebuah tujuan tertentu. Kondisi seseorang tersebut juga mempengaruhi hasil dari tujuan yang diinginkan tersebut.

Terdapat banyak hal yang mempengaruhi kesiapan masyarakat terutama terkait dengan perencanaan perhutanan sosial misalkan keterampilan dan pengetahuan masyarakat dalam menjalankan program perhutanan sosial.

Dalam penentuan kesiapan masyarakat terhadap perencanaan hutan sosial ini terdapat beberapa kriteria sebagai berikut:

a. Kesiapan masyarakat dari aspek biofisik. Contohnya dari ketersediaan lahan peruntukan hutan sosial

b. Kesiapan masyarakat dari aspek kelembagaan. Contohnya lembaga desa dan kelompok tani, dll.

c. Kesiapan masyarakat dari aspek ekonomi. Contohnya tingkat ketergantungan masyarakat serta pendapatan masyarakat, dll.

Berdasarkan kajian teori yang telah dijabarkan sebelumnya maka kerangka koseptual dalam penelitian ini disajikan pada gambar 1 .

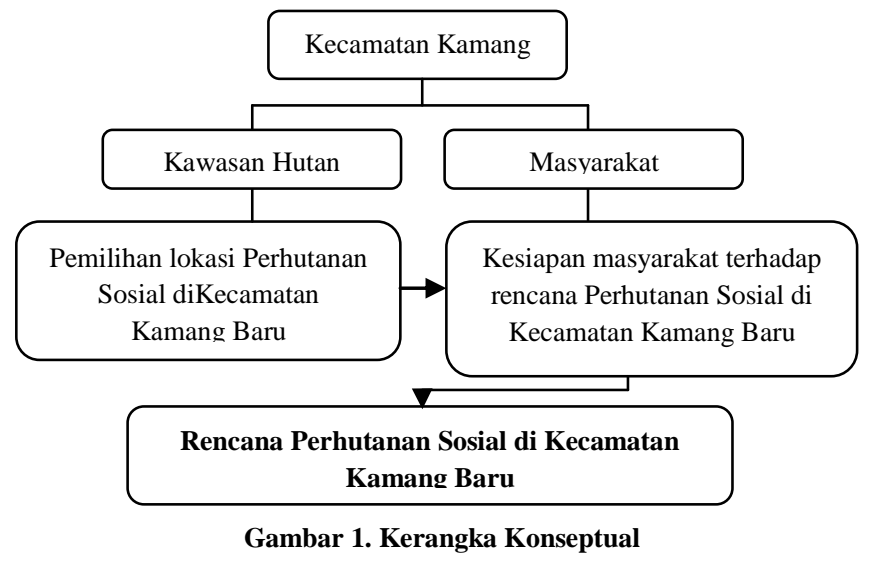

E-ISSN : 2615-2630 


\section{METODE PENELITIAN}

Jenis penelitian ini adalah bersifat penelitian campuran (mixed method), yang bertujuan untuk menggambarkan dan mengungkapkan suatu masalah, keadaan, peristiwa sebagaimana adanya atau mengungkapkan fakta secara lebih mendalam. Penelitian kualitatif merupakan penelitian yang bertujuan untuk mengumpulkan informasi mengenai status suatu gejala yang ada yaitu keadaan gejala menurut apa adanya pada saat penelitian dilakukan (Arikunto, 1989). Sedangkan penelitian secara kuantitatif adalah mengunakan data berupa angka sebagai alat menganalisis keterangan mengenai apa yang ingin diketahui (Kasiram 2008).

Populasi yang terdapat dalam penelitian ini yaitu semua kawasan hutan yang terdapat di Kecamatan Kamang Baru. Pada penelitian ini, semua populasi akan dijadikan sampel, yaitu semua kawasan hutan yang ada di kecamatan kamang baru.

Data dalam penelitian ini menggunakan data primer dan data sekunder. Data primer adalah data yang diperoleh dari sumber pertama atau sumber langsung di lapangan baik bersumber dari individu ataupun kelompok seperti hasil wawancara, kuisioner, dan observasi (Tika, 2005), sedangkan data sekunder adalah data yang diperoleh oleh seorang peneliti tidak secara langsung dari subjek atau objek yang diteliti, tetapi melalui pihak lain seperti instansi atau lembaga terkait, perpustakaan, arsip, perorangan dan sebagainya (Tika, 2005). Dapat dilihat pada tabel 1 .

Tabel 1. Jenis dan Sumber Data

\begin{tabular}{|l|l|l|l|}
\hline No & \multicolumn{1}{|c|}{ Data } & Jenis Data & \multicolumn{1}{c|}{ Sumber data } \\
\hline 1 & $\begin{array}{l}\text { Peta } \\
\text { Administrasi } \\
\text { Kecamatan } \\
\text { Kamang Baru }\end{array}$ & Sekunder & $\begin{array}{l}\text { Bappeda Kabupaten } \\
\text { Sijunjung }\end{array}$ \\
\hline 2 & $\begin{array}{l}\text { Peta kawasan } \\
\text { hutan } \\
\text { Kecamatan } \\
\text { Kamang Baru }\end{array}$ & Sekunder & $\begin{array}{l}\text { Bappeda dan Dinas } \\
\text { Kehutanan Kabupaten } \\
\text { Sijunjung }\end{array}$ \\
\hline 3 & $\begin{array}{l}\text { Peta RTRW } \\
\text { Kecamatan } \\
\text { Kamang Baru }\end{array}$ & Sekunder & $\begin{array}{l}\text { Bappeda Kabupaten } \\
\text { Sijunjung }\end{array}$ \\
\hline 4 & $\begin{array}{l}\text { Peta } \\
\text { Penggunaan } \\
\text { Lahan } \\
\text { Kecamatan } \\
\text { Kamang Baru }\end{array}$ & Sekunder & $\begin{array}{l}\text { Bappeda Kabupaten } \\
\text { Sijunjung }\end{array}$ \\
\hline 5 & $\begin{array}{l}\text { Kesiapan } \\
\text { Masyarakat } \\
\text { Terhadap } \\
\text { Program } \\
\text { Hutan Social }\end{array}$ & Primer & Wawancara dan angket \\
\hline
\end{tabular}

Penelitian ini menggunakan beberapa teknik untuk mendapatkan atau pengumpulan data sesuai dengan jenis dan metode penelitiannya. Adapun teknik yang digunakan adalah dengan cara mewawancarai perangkat desa untuk mengetahui kesiapan masyarakat terhadap program perhutanan sosial di Kecamatan Kamang Baru (observasi, wawancara dan dokumentasi) untuk mengecek kredibilitas data yang di dapat dari instansi.

Penelitian ini menggunakan beberapa teknik untuk mendapatkan atau pengumpulan data sesuai dengan jenis dan metode penelitiannya. Adapun teknik yang digunakan adalah dengan cara mewawancarai perangkat desa untuk mengetahui kesiapan masyarakat terhadap program perhutanan sosial di Kecamatan Kamang Baru (observasi, wawancara dan dokumentasi) untuk mengecek kredibilitas data yang di dapat dari instansi. 
Teknik analisis data terbagi atas dua yaitu:

1. Potensi perhutanan sosial

Analisis ketersediaan lahan hutan sosial ini dilakukan dengan metode tumpang susun (overlay) dengan menggunakan Software GIS. Tahapan adalah sebagai berikut:

a. Peta RTRW Kec. Kamang baru, Peta Penggunaan Lahan, Peta Kawasan Hutan, Peta Perkebunan dan Peta Administrasi ditumpang susun.

b. Selanjutnya melalui proses logical query dengan kriteria lahan untuk hutan sosial didapatkan Peta Ketersediaan Lahan (lahan potensial) untuk pengembangan hutan sosial.

c. Untuk mendapatkan Peta Lahan Prioritas untuk pengembangan hutan sosial dilakukan lagi proses logical query dengan kriteria lahan dengan kelerengan lebih dari $25 \%$.

2. Kesiapan masyarakat terhadap program perhutanan sosial

Terdapat tiga teknik an-alisis data deskriptif yaitu reduksi data, penyajian data dan penarikan kesimpulan (Miles dan Huberman 2005). Pada penelitian ini, untuk mengetahui kesiapan masyarakat terhadap program perhutanan sosial setelah menyebarkan dan mengumpulkan angket kembali, teknik yang digunakan untuk menganalisis data tesebut adalah penyajian data dan penarikan kesimpulan.

Variabel-variabel yang ber-kenaan dengan masalah unit yang diteliti dalam persiapan pe-mbangunan hutan sosial ini, seperti:

a. Kesiapan masyarakat dari aspek biofisik. Contohnya dari ketersediaan lahan peruntukan hutan sosial

b. Kesiapan masyarakat dari aspek kelembagaan. Contohnya lembaga desa dan kelompok tani, dll.

c. Kesiapan masyarakat dari aspek ekonomi. Contohnya tingkat ketergantungan masyarakat serta pendapatan masyarakat, dll.

Untuk mengetahui nilai kesiapan masyarakat kamang baru terhadap perencanaan perhutanan sosial diperoleh dengan rumus:

$$
\mathrm{N}=\frac{\mathrm{R}}{\mathrm{SM}} x 100
$$

Keterangan:

$\mathrm{N}=$ Nilai yang dicari atau

diharapkan

$\mathrm{R}=$ Skor yang diperoleh

$\mathrm{SM}=$ Skor maksimum

$100=$ Bilangan tetap

(Adaptasi dari Purwanto, 2009)

Kategori kesiapan masyarakat dilihat berdasarkan rentang nilai yang diperoleh dari hasil pengolahan data skor kesiapan, sehingga didapatkan hasil kesiapan berupa kategori yang disajikan pada tabel 2. 
Tabel 2. Kategori Kesiapan Masyarakat

\begin{tabular}{|l|l|l|}
\hline No. & Rentang Nilai & Kategori \\
\hline 1 & $0-20$ & Tidak Siap \\
\hline 2 & $21-40$ & Kurang Siap \\
\hline 3 & $41-60$ & Cukup Siap \\
\hline 4 & $61-80$ & Siap \\
\hline 5 & $81-100$ & Sangat Siap \\
\hline
\end{tabular}

(Dimodifikasi dari Poerwanti, 2008)

\section{HASIL DAN PEMBAHASAN}

Analisis data dilakukan untuk menentukan ketersediaan lahan hutan sosial di Kecamatan Kamang Baru Kabupaten Sijunjung dengan metode tumpang tindih (overlay) dengan menggunakan Software GIS.

\section{Pemilihan Lokasi Perhutanan Sosial di Kecamatan Kamang Baru}

Analisis ketersediaan lahan hutan sosial ini dilakukan dengan metode tumpang tindih (overlay) dengan menggunakan Software GIS. Identifikasi ketersediaan lahan untuk pengembangan hutan sosial sebagai berikut :

a. Peta RTRW Kec. Kamang baru, Peta Penggunaan Lahan, Peta Kawasan Hutan, dan Peta Administrasi ditumpang tindihkan.

b. Selanjutnya melalui proses logical query dengan kriteria lahan untuk hutan sosial didapatkan Peta Ketersediaan Lahan (lahan potensial) untuk pengembangan hutan sosial.

c. Untuk mendapatkan Peta Lahan Prioritas untuk pengembangan hutan sosial dilakukan lagi proses logical query dengan kriteria lahan dengan kelerengan lebih dari $25 \%$.
Berdasarkan kiriteria identi-fikasi di atas akan dijabarkan mengunakan peta dengan teknik analisis tumpang susun (overlay) sebagai berikut :

a. Peta Administrasi Kecamatan Kamang Baru

Kecamatan Kamang Baru merupakan salah satu kecamatan yang berada pada Kabupaten Sijunjung yang memililiki 11 kenagarian yang terdapat didalam nya, berikut nagari-nagari yang ada di Kecamatan Kamang Baru yang akan dijadikan lokasi pemilihan lokasi perhutanan sosial disajikan pada tabel 3.

Tabel 3. Nagari-Nagari di Kecamatan Kamang Baru

\begin{tabular}{|l|l|r|}
\hline No & \multicolumn{1}{|c|}{ Nagari } & \multicolumn{1}{c|}{ Luas $\mathbf{( k m}^{2} \mathbf{)}$} \\
\hline 1 & Sungai Lansek & 48.66 \\
\hline 2 & Muaro Takuang & 29.41 \\
\hline 3 & Kumpar & 188.39 \\
\hline 4 & Kamang & 177.95 \\
\hline 5 & Aia Amo & 101.25 \\
\hline 6 & Sungai Betung & 59.23 \\
\hline 7 & Siaur & 9.49 \\
\hline 8 & Lubuk Trantang & 91.52 \\
\hline 9 & Maloro & 69.64 \\
\hline 10 & Tanjuang Kaliang & 116.03 \\
\hline 11 & Padang Tarok & 37.57 \\
\hline & Jumlah luas & 837.80 \\
\hline
\end{tabular}

Sumber : BPS Kecamatan Kamang Baru Dalam Angka 2017

b. Peta Rencana Tataruang Wilayah Kecamatan Kamang Baru

Peta Rencana Tata Ruang Wilayah Kecamatan Kamang Baru merupakan salah satu peta yang digunakan dalam proses penentuan lokasi perhutanan sosial yang ada dikecamatan kamang baru, peta 
rencana tataruang ini berfungsi sebagai penentu agar lokasi yang perhutanan sosial yang dipilih agar tidak berada pada kawasan rencana tataruang wilayah yang ditetapkat sebagai zona khusus seperti zona industri misalnya.

c. Peta Penggunaan Lahan Kecamatan Kamang Baru

Dalam pemilihan lokasi perhutanan sosial peta penggunaan lahan menjadi salah satu data yang sangat dibutuhkan untuk dapat melihat bagaimana penggunaan lahan yang ada di kecamatan kamang baru, sehingga dapat memudahkan dalam pemilihan lokasi perhutanan sosial, berikut penggunaan lahan yang terdapat pada peta penggunaan lahan kecamatan kamang baru disajikan pada tabel 4.

Tabel 4. Penggunaan Lahan Kec. Kamang Baru

\begin{tabular}{|r|l|r|}
\hline NO & Penggunaan Lahan & Luas (ha) \\
\hline 1 & Hutan & 48.405 \\
\hline 2 & Kampung/ permukiman & 1.479 \\
\hline 3 & Perkebunan & 19.807 \\
\hline 4 & Kebun campuran & 1.085 \\
\hline 5 & Sawah Beririgasi & 2.870 \\
\hline 6 & Sawah non irigasi & 488 \\
\hline 7 & Padang Belukar & 3.609 \\
\hline 8 & Tanah Rusak/ Kering & 5.762 \\
\hline 9 & Lainya & 269 \\
\hline
\end{tabular}

Sumber : Penggunaan Lahan Kecamatan Kamang Baru

d. Peta Kawasan Hutan Kecamatan Kamang Baru

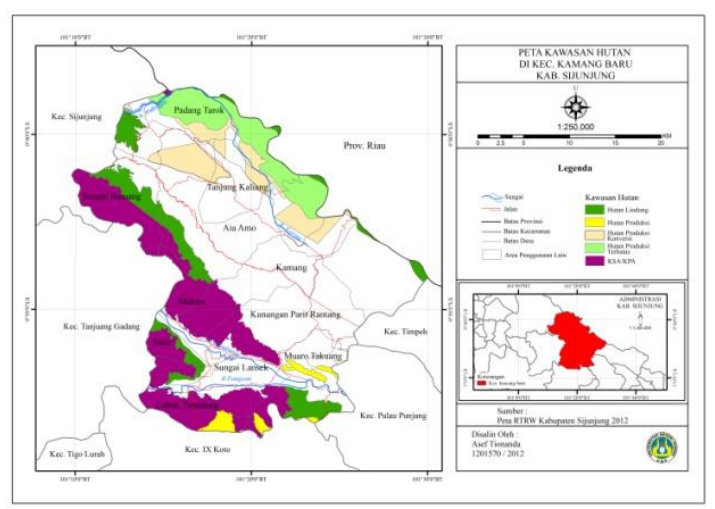

Gambar 2. Peta Kawasan Hutan Kec. Kamang Baru

Dalam pemilihan lokasi perhutanan sosial peta kawasan hutan memiliki peranan penting untuk dapat menentukan lokasilokasi potensial yang akan dijadikan perhutanan sosial, perhutanan sosial berdasarkan kriteria yang ada terdapat pada hutan lindung dan hutan produksi, kedua kriteria tersebut dapat dilihat pada klasifikasi kawasan hutan pada tabel 5.

Tabel 5. Kawasan Hutan Kec. Kamang Baru

\begin{tabular}{|r|l|r|}
\hline NO & $\begin{array}{c}\text { Klasifikasi Kawasan } \\
\text { Hutan }\end{array}$ & Luas (Ha) \\
\hline 1 & KSA/KPA & 15.002 \\
\hline 2 & Hutan Lindung & 5.733 \\
\hline 4 & Area Penggunaan Lain & 41.781 \\
\hline 5 & Hutan Produksi & 1.197 \\
\hline 7 & Hutan Produksi Konversi & 5.114 \\
\hline 8 & Hutan Produksi Terbatas & 5.629 \\
\hline \multicolumn{3}{|c|}{ Sumber:asan Sumber: Kawasan Hutan } \\
Kecamatan Kamang Baru
\end{tabular}

e. Peta Ketersediaan Lokasi Potensial Perhutanan Sosial Kecamatan Kamang Baru

Untuk mendapatkan Peta Ketersediaan Lokasi Potensial 
Perhutanan Sosial Kecamatan Kamang Baru maka dilakukan overlay beserta proses query logika boolean dengan kriteria lahan untuk hutan sosial pada ke empat peta di atas.

Metode overlay yang digunakan dalam menganalisis peta mengunakan prinsip-prinsip logika Boolean yang mempunyai 2 nilai, yaitu true atau false (benar atau salah) nilai true bisa digantikan dengan 1 dan nilai false digantikan dengan 0 .

Berdasarkan metode diatas overlay Peta Administrasi Kecamatan Kamang Baru, Peta RTRW Kecamatan Kamang Baru, Peta Penggunaan Lahan Kecamatan Kamang Baru, dan Peta kawasan hutan kecamatan kamang baru, didapatkan Peta Ketersediaan Lahan (lahan potensial) untuk pengembangan hutan sosial pada gambar 3.

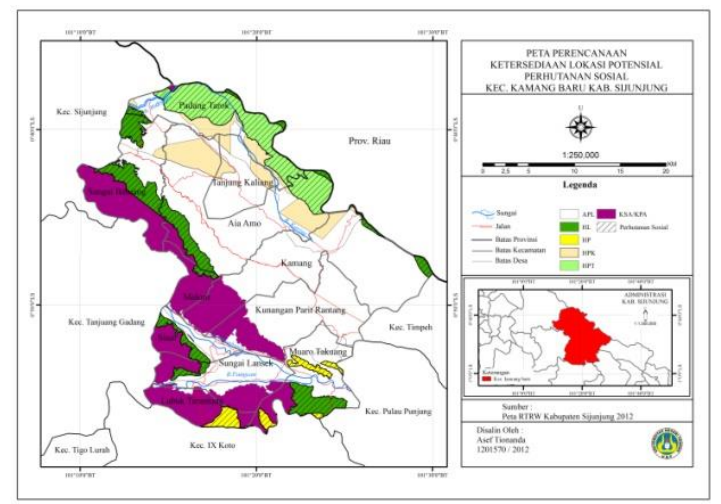

Gambar 3. Peta Ketersediaan Lokasi Potensial Perhutanan Sosial Kec. Kamang Baru

Ketersediaan lokasi potensial perhutanan sosial di setiap nagari yang ada di Kecamatan Kamang
Baru, Nagari Kamang terletak pada kawasan hutan lindung, Padang Tarok pada kawasan hutan lindung dan hutan produksi terbatas, Maloro pada hutan lindung, lubuk tarantang pada hutan produksi, Siaur pada hutan lindung, Sungai Batuang pada hutan lindung, Aia Amo pada hutan lindung dan hutan produksi terbatas, Muaro Takuang pada hutan lindung dan hutan produksi, Sungai Lansek pada kawasan hutan lindung dan kawasan hutan produksi.

f. Peta Ketersediaan Lokasi Prioritas Perhutanan Sosial Kecamatan Kamang Baru

Dari proses pemilihan lokasi potensial dicari pula lokasi prioritas pengembangan perhutanan sosial dengan melakukan overlay antara Peta Lokasi Potensial Pengembangan Perhutanan Sosial dan Peta Lereng, selanjutnya dilakukan proses logical query kriteria lahan dengan kelerengan lebih dari $25 \%$, lokasi prioritas perhutanan sosial dapat dilihat pada gambar 4 .

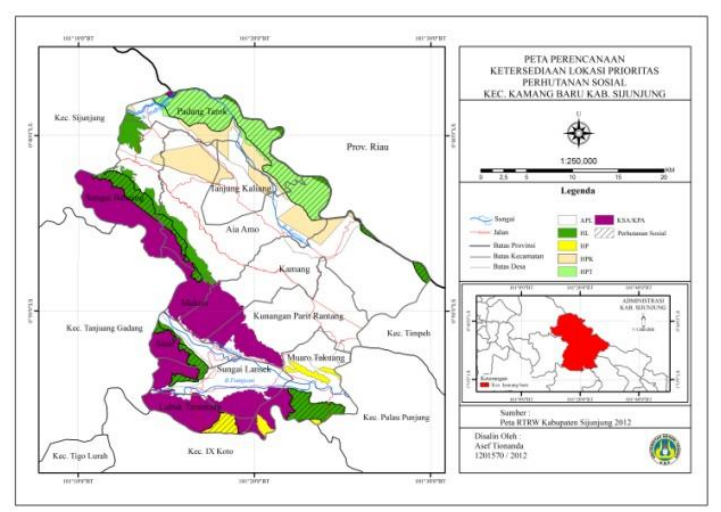

Gambar 4. Peta perencancanaan lokasi prioritas perhutanan sosial di kec. Kamang Baru

E-ISSN : $2615-2630$ 
Kecamatan Kamang Baru yang memiliki sumber daya hutan yang luas yang tersebar di 11 kenagarian sehingga sangat berpotensi dijadikan perhutanan sosial, berdasarkan hasil analisis overlay yang diterjemahkan dalam peta di atas didapatlah 7 nagari yang memiliki potensi perhutanan sosial dengan luas yang berbeda beda.

Berdasarkan tabel 6 , terlihat bahwa pada Nagari Padang Tarok memiliki potensi lokasi prioritas perhutanan sosial yang sangat besar dengan luas 4.181 ha, sedangkan luasan yang paling sedikit terdapat pada Nagari Maloro dengan luas 73 ha. Potensi lokasi prioritas perhutanan sosial lainya Nagari Aia Amo dengan luas 1.784 ha, Nagari Muaro Takuang dengan luas 318 ha, Nagari Sungai Betung dengan luas 955 ha, Nagari Siaur dengan luas 380 ha, dan Nagari Sungai Lansek dengan luas 265 ha.

Tabel 6. Luas Perhutanan sosial di Kecamatan Kamang Baru

\begin{tabular}{|l|l|r|}
\hline No & \multicolumn{1}{|c|}{ Nagari } & \multicolumn{2}{c|}{$\begin{array}{c}\text { Luas perhutanan } \\
\text { sosial (ha) }\end{array}$} \\
\hline 1 & Sungai Lansek & 265 \\
\hline 2 & Muaro Takuang & 318 \\
\hline 3 & Aia Amo & 1.784 \\
\hline 4 & Maloro & 73 \\
\hline 5 & Padang Tarok & 4.181 \\
\hline 6 & Sungai Batuang & 955 \\
\hline 7 & Siaur & 380 \\
\hline & Jumlah & 7.956 \\
\hline
\end{tabular}

Sumber : Berdasarkan hasil analisis peta pemilihan lokasi prioritas perhutanan sosial Kecamatan Kamang Baru
2. Kesiapan Masyarakat Terhadap Rencana Pengembangan Perhutanan Sosial di Kecamatan Kamang Baru

Dari 11 nagari yang ada dikecamatan kamang baru didapat 9 nagari yang memiliki lokasi perencanaan perhutanan sosial, berdasarkan pemilihan lokasi prioritas perhutanan sosial, untuk menentukan kesiapan masyarakat terhadap perencanaan perhutanan sosial telah dilakukan terlebih dahulu survey awal pada Nagari Sungai Lansek, yang merupakan salah satu nagari yang telah lebih dahulu melakukan pengajuan permohonan perencanaan perhutanan sosial berupa hutan nagari, maka dari itu peneliti dapat membandingkan bagaimana kesiapan masyarakat terhadap perencanaan hutan sosial nagari lain yang ada di Kecamatan Kamang Baru.

Dalam penentuan kesiapan masyarakat terhadap perencanaan hutan sosial ini terdapat beberapa kriteria sebagai berikut:

a. Kesiapan masyarakat dari aspek biofisik. Contohnya dari ketersediaan lahan peruntukan hutan sosial

b. Kesiapan masyarakat dari aspek kelembagaan. Contohnya lembaga desa dan kelompok tani, dll.

c. Kesiapan masyarakat dari aspek ekonomi. Contohnya tingkat 
ketergantungan masyarakat serta pendapatan masyarakat, dll.

Kriteria diatas kemudian dikembangkan menjadi pertanyanpertanyaan yang diberi bobot sehingga dapat menentukan kesiapan masyarakat terhadap perencanaan perhutanan sosial di masing-masing nagari yang ada di Kecamatan Kamang Baru berikut hasil wawancara pada setiap nagari yang di jadikan acuan dalam pembobotan kesiapan masyarakat terhadap perencanaan hutan sosial.

Hasil wawancara diolah dengan mengacu kepada kriteriakriteria tentang kesiapan masyarakat terhadap rencana pengembangan perhutanan sosial di Kecamatan Kamang Baru, sehingga didapatkan hasil kesiapan masyarakat yang terdapat pada tabel 7.

Tabel 7. Skor kesiapan masyarakat terhadap perencanaan perhutanan sosial

\begin{tabular}{|c|l|c|}
\hline No & \multicolumn{1}{|c|}{ Nama Nagari } & Skor \\
\hline 1 & Sungai Lansek & 80 \\
\hline 2 & Muaro Takuang & 80 \\
\hline 3 & Kamang & 10 \\
\hline 4 & Aia Amo & 70 \\
\hline 5 & Maloro & 10 \\
\hline 6 & Padang Tarok & 10 \\
\hline 7 & Sungai Betung & 90 \\
\hline 8 & Siaur & 50 \\
\hline 9 & Lubuk Tarantang & 90 \\
\hline
\end{tabular}

Sumber : Berdasarkan Hasil Analisis Datakesiapan Masyarakat

Pada tabel 7 dapat dilihat skor kesiapan masyarakat terhadap perencanaan perhutanan sosial di Kecamatan Kamang Baru, nagari yang memiliki skor tertinggi terdapat pada Nagari Sungai Betung dan Lubuk Tarantang dengan skor 90, Nagari Sungai Lansek, Dan Muaro Takuang dengan skor 80, Nagari Aia Amo dengan skor 70 sedangkan Nagari yang memiliki skor terendah terdapat pada Nagari Kaman, Maloro, Dan Padang Tarok dengan skor 10.

rhadap rencana pengembangan perhutanan sosial merupakan hal penting setelah dilakukan pemilihan lokasi prioritas perhutanan sosial. Ditentukan berdasarkan kriteriakriteria kesiapan masyarakat sehingga didapat kan skor pada masing-masing nagari yang ada di Kecamatan Kamang Baru, dan kemuadian dilakukan pengkategorian dengan panduan yang terdapat pada tabel 8 .

Tabel 8. Kategori Kesiapan Masyarakat Terhadap Perencanaan Perhutanan Sosial

\begin{tabular}{|l|l|l|}
\hline No. & Rentang nilai & Kategori \\
\hline 1 & $0-20$ & Tidak Siap \\
\hline 2 & $21-40$ & Kurang Siap \\
\hline 3 & $41-60$ & Cukup Siap \\
\hline 4 & $61-80$ & Siap \\
\hline 5 & $81-100$ & Sangat Siap \\
\hline \multicolumn{2}{|c|}{ Sumber $:$ Modifikasi dari Poerwanti 2008 } \\
\hline
\end{tabular}

Pada tabel 9 di dapat dilihat kesiapan masyarakat terhadap Perencanaan Perhutanan Sosial di Kecamatan Kamang Baru, nagari yang memiliki kategori sangat siap yaitu (Nagari Lubuk Tarantang dan Nagari Sungai Betung), nagari dengan 
kategori siap yaitu (Nagari Sungai Lansek, Nagari Muaro Takuang, dan Nagari Aia Amo), nagari dengan kategori cukup siap yaitu (Nagari Siaur), nagari dengan kategori tidak siap yaitu ( Nagari Maloro, Nagari Kamang, dan Nagari Padang Tarok)

Tabel 9. Kesiapan Masyarakat Terhadap Perencanaan Perhutanan Sosial Kecamatan Kamang Baru

\begin{tabular}{|l|l|r|c|}
\hline No & \multicolumn{1}{|c|}{ Nama Nagari } & \multicolumn{1}{c|}{ Skor } & Kesiapan \\
\hline 1 & Sungai Lansek & 80 & Siap \\
\hline 2 & Muaro Takuang & 80 & Siap \\
\hline 3 & Kamang & 10 & Tidak siap \\
\hline 4 & Aia Amo & 70 & Siap \\
\hline 5 & Maloro & 10 & Tidak siap \\
\hline 6 & Padang Tarok & 10 & Tidak siap \\
\hline 7 & Sungai Betung & 90 & Sangat siap \\
\hline 8 & Siaur & 50 & Cukup siap \\
\hline 9 & Lubuk Tarantang & 90 & Sangat siap \\
\hline \multicolumn{4}{|c|}{ Sumber : Berdasarkan Hasil Pengolahan } \\
\multicolumn{4}{|c|}{ Data Kesiapan Masyarakat } \\
\hline
\end{tabular}

Berdasarkan tabel 9 kesiapan masyarakat terhadap Perencanaan Perhutanan Sosial Kecamatan Kamang Baru dapat digambarkan kedalam sebuah peta yang dapat dilihat pada gambar 5 dibawah ini.

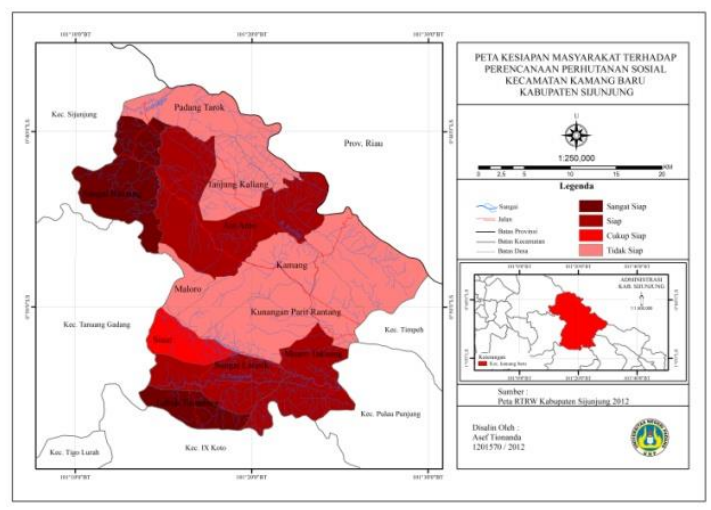

Gambar 5. Peta Kesiapan Kesiapan

Masyarakat Kecamatan Kamang Baru

\section{PENUTUP}

\section{Kesimpulan}

Berdasarkan hasil penelitian mengenai pemilihan lokasi perhutanan sosial di Kecamatan Kamang Baru dapat disimpulkan bahwa:

1. Lokasi-lokasi prioritas perhutanan sosial beserta luasan nya sebagai berikut:

a. Sungai Lansek dengan luas 265 ha

b. Muaro Takuang dengan luas 318 ha

c. Aia Amo dengan luas 1784 ha

d. Maloro dengan luas 73 ha

e. Padang Tarok dengan luas 4181 ha

f. Sungai Betung dengan luas 955 ha

g. Siaur dengan luas 380 ha

h. Jumlah luas keseluruhan perhutanan sosial kecamatan kamang baru 7956 ha

2. Kondisi kesiapan masyarakat terhadap perencanan perhutanan sosial yang dilakukan kepada setiap perangkat nagari yang ada di Kecamatan Kamang Baru mendapatkan hasil sebagai berikut :

a. Sungai Lansek dengan kategori siap

b. Muaro Takuang dengan kategori siap

c. Kamang dengan kategori tidak siap

d. Aia Amo dengan kategori siap

e. Maloro dengan kategori tidak siap

f. Padang Tarok dengan kategori tidak siap

g. Sungai Betung dengan kategori sangat siap 
h. Siaur dengan kategori cukup siap

i. Lubuk Tarantang dengan kategori sangat siap

j. Kunangan Parit Rantang dengan kategori tidak siap

k. Tanjuang Kaliang dengan kategori tidak siap

\section{Saran}

Berdasarkan pembahasan dan kesimpulan, maka peneliti dapat memberikan saran sebagai berikut:

1. Pada Pemerintah setempat agar dapat menjadi sumbangan ide dalam menentukan kebijakan dalam penyelenggaraan program perhutanan sosial di Kecamatan Kamang Baru

2. Pada pemerintah setempat agar dapat menyusun perencanaan pembangunan dan kebijakan seperti penyuluhan kepada pemerintah nagari dan masyarakat di Kecamatan Kamang Baru terdadap program perhutanan sosial

3. Pada masyarakat agar meningkatkan antusiasme serta berperan aktif dalam terlakasana nya program perencanaan perhutanan sosial.

\section{DAFTAR PUSTAKA}

Arikunto,S. 2014. Prosedur Penelitian. Jakarta: PT. Rineka Cipta

Arikunto, S. 1989. Prosedur Penelitian: Suau Pendekaan Praktik. Jakarta: Bumi Aksara.

CIFOR. 2012. Warta kebijakan. Buku. CIFOR. Bogor.
Hakim, I. 2010. Social Forestry Мепији Restorasi Pembangunan Kehutanan

Berkelanjutan. Buku. Pusat Penelitian dan Pengembangan Perubahan Iklim dan Kebijakan. Bogor.

Kasiram, 2008. Metodologi Penelitian. Malang: UIN-Malang Pers

Kementrian Lingkugan Hidup Dan Kehutanan Republic Indonesia. 2005. Statistik Kementrian Lingkugan Hidup Dan Kehutanan. Jakarta: Depertemen Kehutanan

Miles, Huberman 2005. Qualitative Data Analysis (terjemahan). Jakarta: UI Press.

Tika. 2005. "Metode Penelitian Geografi”. Jakarta. PT Bumi Aksara.

POKJA timbulun. 2014. "Pengelolaan Hutan Berbasis Kearifan Lokal'. Padang. Arifha

Slameto. 2010. Belajar dan faktor-faktor yang mempengaruhinya. Jakarta: PT. Rineka Cipta

Purwanto. 2009. Evaluasi Hasil Belajar. Surakarta: Pustaka belajar

Poerwanti. 2008. Evaluasi Belajar. Bandung: Sinar Baru 